\title{
A SAÚDE DO TRABALHADOR: CONTRAPONTOS ACERCA DAS AÇÕES DIVULGADAS EM PERFIS DE EMPRESAS
}

\author{
Rosângela Rocio Jarros Rodrigues \\ Universidade Estadual de Londrina - UEL, Departamento de Psicologia Social e Institucional, , Londrina, PR. E-mail: \\ jarros@uel.br
}

\begin{abstract}
RESUMO
O trabalho pode ter uma ação muito benéfica para a vida das pessoas. Entre essas está aquela que se constitui como meio de inserção em grupos sociais mais ampliados, onde outros tipos de relacionamentos são estabelecidos e novas tarefas são desenvolvidas, não se restringindo ao meio familiar. Também a saúde pode ser favorecida pelo tipo de trabalho que se executa ou o seu oposto. Este artigo tem por objetivos apresentar as ações voltadas para a saúde do trabalhador e estabelecer os contrapontos em relação à dimensão causal relacionada às condições de trabalho. Essas ações foram empreendidas por empresas no período de 2000 a 2010 e estão contidas na revista as Melhores Empresas para se Trabalhar, publicada pela Editora Abril, especificamente aquelas que foram divulgadas na seção dos perfis "as dez melhores empresas". Este relato resulta da pesquisa que empregou o método histórico e documental para sua execução e que utilizou a técnica de Análise de Conteúdo para categorizar e interpretar os dados obtidos. Os resultados indicam que as empresas adotam ações na prevenção e na mediação dos problemas de saúde dos trabalhadores. Concluímos que há indícios das condições de trabalho estar contribuindo para o adoecimento do trabalhador.
\end{abstract}

Palavras-chave: Qualidade de vida, Saúde do Trabalhador, Trabalho, Organizações.

\section{WORKER'S HEALTH: CONTERPOINTS ON THE SHARES DISCLOSED IN PROFILES OF COMPANIES}

\begin{abstract}
The work can be a very beneficial for people's lives. Among these is that constitutes as means of insertion into social groups expanded, where other types of relationships are established and new tasks are developed not by restricting the kind of familiar. Health also may be favored by the kind of work that performs or it is opposite. This article aims to present the actions directed to the worker's health and establish the counterpoints regarding the causal dimension related to working conditions. These actions were undertaken by companies in the period from 2000 to 2010 and are contained in the magazine the best companies to work for, published by April, specifically those that were disclosed in the section of profiles "top ten companies". This report is the result of research that employed the historical and of document method for its implementation and which used the technique of Content Analysis to categorize and to interpret the data obtained. The results indicate that companies adopt both actions aimed at prevention and at mediation of health problems of workers. We conclude that there is evidence of working conditions is contributing to the illness of the worker.
\end{abstract}

Keywords: Quality of life, Worker's health, Work, Organizations. 


\section{INTRODUÇÃO}

Como compreender o homem sem conhecer a atividade que executa? Desconhecer as tarefas realizadas, as condições de trabalho (ritmo, jornada, temperatura, duração) a que são submetidos, as metas predeterminadas, o estilo de liderança dos superiores e o modo de gestão da organização dificultam ainda mais a análise das implicações do cotidiano laboral sobre a saúde do trabalhador.

Quando Codo, Soratto e Vasques-Menezes (2011, p. 282) descrevem as três abordagens dos estudos em saúde mental, apontam que o estresse seria como "um estado intermediário entre a saúde e a doença, passa a ser um possível indicador das consequências do trabalho sobre os trabalhadores, que podem estar sofrendo em decorrência das condições e características de sua atividade, sem necessariamente apresentar nenhum estado patológico definido". Logo destacam as consequências do trabalho para a qualidade de vida dos trabalhadores.

Na mesma direção Silva (1992) ressaltava que há circunstâncias no trabalho onde pressões fortes provocam o cansaço e a tensão emocional nos trabalhadores. Pressões internas às organizações que são resultantes da intensificação da produção, das mudanças relacionadas à cultura organizacional ou aos processos tecnológicos para execução das tarefas e, também, quando aliadas às pressões externas como recessão econômica intensifica as exigências mentais e emocionais que podem propiciar o aumento das crises de ansiedade com reações psicossomáticas. Ainda Silva (1992) enfatiza que, a natureza, o conteúdo da tarefa, a duração das jornadas de trabalho e o controle exercido sobre os trabalhadores, são capazes de gerar adoecimentos.

Corroborando a ideia que o modo de gestão a que estão submetidos os trabalhadores podem influenciar diretamente a saúde, Chanlat (1995) considera que o modo tayloriano que pressupõe a repetição das tarefas, a pressão do tempo, a carga física penosa, a ausência de autonomia entre outras variáveis, determinem os numerosos problemas de saúde, tanto física quanto mental e que além das enfermidades de ordem física e/ou mental (fadiga crônica, úlceras, doenças cardiovasculares, musculares e ósseas, insônias, neuroses, depressão) é possível observar o envelhecimento acelerado dos trabalhadores. Diz Chanlat (1995, p.124) que a saída para o impasse nas organizações é modificar "antes de tudo, atingir a organização do trabalho e as suas condições".

Lima (1997, p. 57) já recomendava que as pesquisas em saúde mental e trabalho partissem da "apreensão das formas concretas da atividade de trabalho e na explicitação dos impactos sobre os indivíduos". Desse modo, evitaríamos a visão de causalidade dos problemas de saúde a partir 
apenas da dimensão da individualidade (constituição física, hábitos, história de vida...) do trabalhador. Conforme Borges, Guimarães e Silva (2013) as organizações podem cooperar para a promoção e a prevenção da saúde por meio da adoção de políticas apropriadas, atentando que o trabalho tem um papel estruturante na vida humana.

O objetivo então é identificar as ações voltadas para a saúde do trabalhador que foram divulgadas no gênero textual em questão e, a partir da análise dos dados, estabelecerem contrapontos embasados na literatura da área de Psicologia do Trabalho acerca das condições que rodeiam os trabalhadores e que podem contribuir para o seu adoecimento.

\section{MÉTODO}

O método é o da pesquisa histórica, portanto, descritiva (GIL, 2008) porque tem por finalidade a descrição e o estudo das características que marcam a evolução histórica de determinado fenômeno. Tem como fonte de dados documentos de domínio público (SPINK, 2004, p.126), esses “[...] são documentos tornados públicos, sua intersubjetividade é produto da interação com um outro desconhecido, porém significativo e frequentemente coletivo". Os documentos permanecem ao longo do tempo, considerando-se que sua origem dá-se em um determinado contexto histórico, social, cultural e econômico.

Os documentos analisados são dez exemplares do gênero textual da Revista Exame Você S.A., "As Melhores Empresas para se Trabalhar no Brasil", publicada anualmente pela Editora Abril. O período em estudo abrange 2000 a 2010, a seção dos perfis "As 10 Melhores Empresas", totalizando 110 textos.

A análise dos dados seguiu à técnica de Análise de Conteúdo de Lawrence Bardin (1979) a fim de categorizar e interpretar os dados. A técnica abrange o desenvolvimento de três fases organizadas cronologicamente que são a análise preliminar dos textos, a codificação do material e a interpretação.

\section{RESULTADOS}

Apresentamos nesta seção as ações empreendidas pelas empresas e as exemplificamos com trechos extraídos dos exemplares da revista. Na sequência, exibimos uma tabela com o ano da revista, a quantidade de empresas que divulgam as ações conforme o ano da publicação e a identificação que é de domínio público. 
Tabela1. Empresas que registram em seus perfis ações voltadas para a saúde do trabalhador

\begin{tabular}{|c|c|l|}
\hline $\begin{array}{c}\text { Ano da } \\
\text { Revista }\end{array}$ & $\begin{array}{c}\text { Quantidade de } \\
\text { empresas }\end{array}$ & \multicolumn{1}{|c|}{ Nome das empresas } \\
\hline 2000 & 7 & $\begin{array}{l}\text { Fiat, ABB petroquímica, Arvin Meritor, HP, Merkin, Renner e } \\
\text { Xerox. }\end{array}$ \\
\hline 2001 & 4 & Casa Verde, Redecard, Embraco e Todeschini. \\
\hline 2002 & 6 & Redecard, Movelar, AES SUL, Marcopolo, Algar e Todeschini. \\
\hline 2003 & 7 & $\begin{array}{l}\text { Magazine Luiza, Redecard, Todeschini, Marcopolo, Tigre, Mc } \\
\text { Donald's, Bank Boston. }\end{array}$ \\
\hline 2004 & 6 & $\begin{array}{l}\text { Todeschini, Landis+Gyr, Magazine Luiza, Redicard, Promon e } \\
\text { Zanzini. }\end{array}$ \\
\hline 2005 & 6 & $\begin{array}{l}\text { Todeschini, Credicard, Randon, Zanzini, Serasa e Multibrás da } \\
\text { Amazônia. }\end{array}$ \\
\hline 2006 & 9 & $\begin{array}{l}\text { Masa, BV Financeira, Serasa, Landis+Gyr, Arcelor, Eurofarma, } \\
\text { Fras-le, Accor e Albras. }\end{array}$ \\
\hline 2007 & 6 & Masa, Albras, Landis+Gyr, Volvo, Caterpillar e Hoken. \\
\hline 2008 & 8 & $\begin{array}{l}\text { Volvo, Masa, Caterpillar, Landis+Gyr, Sabin, Promon, Albras e } \\
\text { Serasa. }\end{array}$ \\
\hline 2009 & 4 & BV Financeira, CPFL, Plascar e Landis+Gyr. \\
\hline 2010 & 5 & Volvo, BV Financeira, Sama, Coelce e Dupont. \\
\hline Total & 68 & 41 empresas distintas \\
\hline
\end{tabular}

Vimos que dos 110 textos analisados, 68 deles, portanto, 62\% indicaram algum tipo de manifestação de ação voltada para a promoção e mediação da saúde. Considerando as empresas classificadas no período de 2000 a 2010, essas somam ao todo 41 empresas distintas, pois algumas permaneceram classificadas em mais de um ano. As empresas são advindas do setor comercial, bancário, de energia, automotivo, de alumínio e petroquímica, de engenharia e da área da saúde.

As ações divulgadas pelas empresas ocorrem principalmente por meio da oferta de planos de saúde (serviços externos às empresas) ou no ambulatório (no espaço interno das empresas). Os planos de saúde se dividem entre aqueles subsidiados totalmente pelo empregador e outros que são compartilhados com os trabalhadores. Alguns são exclusivos aos empregados, outros se estendem ao cônjuge (inclusive quando do mesmo sexo), aos filhos, aos pais e aos sogros.

A cobertura dos planos de saúde abrange predominantemente as áreas da medicina, da odontologia e da psicologia. Destarte constatamos o aumento crescente da oferta de serviços na área nutricional, com o objetivo de reeducação alimentar dos trabalhadores. As empresas têm investido e incentivado os mesmos a reduzirem o peso, como citado pela empresa Coelce (REVISTA, 2010, p.88) "tem até um programa que chamamos carinhosamente de QLB, sigla para 'que lapa de bucho', brinca um gestor [...] para explicar o programa que visa à redução de peso". 
À vista disso, no tocante a saúde física, desde 2002 as empresas mencionam o investimento em ginástica laboral realizada no horário de trabalho incluindo o noturno e, em geral, esse serviço é prestado por profissionais terceirizados. Diz um funcionário da Landis+Gyr (REVISTA, 2009, p.102) que a empresa oferece "acompanhamento ergonômico e postural, ginástica laboral [...]". Todavia, tem empresa onde esse serviço não é oferecido para trabalhadores do setor da produção. Igualmente há incentivos para prática de exercícios em academias e caminhadas em espaço próximo às empresas, como é o caso da Hoken (REVISTA, 2007, p.94) que "uma vez por mês, o expediente termina mais cedo, às quatro da tarde. É o Hoken Day. Nesse dia, os colaboradores vestem roupa de ginástica e vão fazer uma caminhada até a represa que fica próxima à companhia". Também algumas empresas promovem atividades como massagem, ioga, reike e florais.

Com o foco nas emoções, duas empresas referiram o desenvolvimento de programas específicos como o 'emociograma' e a 'terapia do riso'. A empresa Fiat (REVISTA, 2000, p.46) explica o primeiro: "quando a situação em casa não vai bem, o funcionário pode usar o 'emociograma'. Trata-se de um quadro em que cada empregado expressa seu estado emocional no dia. Nesse caso os colegas e chefes atuam como conselheiros". A empresa Serasa (REVISTA, 2005) propõe a terapia do riso como meio do trabalhador descansar da rotina de trabalho. Assim, "os funcionários do call center têm fonoaudiólogos, além de uma confortável sala de descompressão, para descansar da rotina exaustiva. [...] até terapia do riso; massagista" (REVISTA, 2005, p.52).

Igualmente às ações, as empresas relatam que proporcionam programas de médio em longo prazo como o Programa de Desenvolvimento Individual (PDI), o Programa Viva Melhor e a Segunda Opinião.

O PDI é ofertado pela Algar (REVISTA, 2002, p.63):

O Programa de Desenvolvimento Individual (PDI), por sua vez, é um treinamento de desenvolvimento profissional personalizado que leva dois anos e é avaliado anualmente. Em 2002, o PDI ganhou outra versão: o PDI da Saúde. O objetivo do novo programa é fazer com que a saúde e a qualidade de vida dos executivos do grupo melhorem significativamente. Para isso, uma equipe multidisciplinar - que inclui médico, nutricionista e personal trainer estabelece metas para cada um dos associados, tudo com anuência deles, claro. As metas estão atreladas a uma série de fatores: perda de peso, dieta para controle da glicose e do colesterol, avaliação postural, combate ao tabagismo e ao estresse, etc. Os objetivos do PDI da saúde são anuais, e quem consegue cumpri-los ganha uma soma em dinheiro que pode chegar a $20 \%$ do valor total gerado pelos outros programas de incentivo da empresa. 
O 'Programa Viva Melhor' e 'Segunda Opinião' são proporcionados pela Accor (REVISTA, 2006, p.85) onde "O Programa Viva Melhor cuida da gestão do plano de saúde e de tudo o que tem a ver com o bem-estar dos funcionários. Em caso de cirurgias ou terapias especiais, há o programa como Segunda Opinião, que encaminha o funcionário para ouvir outro médico".

Há outro programa prestado pela empresa Marcopolo (REVISTA, 2002, p.61) é o 'Programa Vida' que "promove atividades educativas e tem objetivo de melhorar a qualidade de vida dos colaboradores e seus familiares. A empresa ajuda também a pagar tratamento de dependentes químicos e de tabaco". Aliás, verificamos que entre os anos de 2002 a 2007 e em 2010 foram recorrentes os programas voltados para o tratamento de dependentes químicos, de tabagismo e de alcoolismo pelas empresas.

\section{DISCUSSÃO}

Paralelamente à coleta de dados sobre ações das empresas que objetivavam a promoção e a mediação da saúde, fomos investigando aqueles conteúdos que poderiam desvelar, mesmo que na superfície, o cotidiano de trabalho. Antes de iniciar a discussão estabelecendo os contrapontos é importante ressaltarmos que são valorosas todas as ações e os programas, os investimentos e os incentivos que as empresas adotam no cuidado com a saúde do trabalhador no ambiente organizacional. Igualmente consideramos que essas ações convergem para dois objetivos perseguidos diuturnamente pela a área de Gestão de Pessoas ou de Recursos Humanos das empresas, são eles a redução dos índices de absenteísmo e de tunover (CHIAVENATO, 2004).

Salientamos que o plano de saúde é um benefício social que a empresa utiliza, portanto para atrair e manter os trabalhadores na empresa. Desse modo, tende a compor o salário do trabalhador evitando com que esse se desligue da empresa e o tunover seja reduzido, como vemos no caso da Sabin "com um generoso pacote de vantagens e condições de trabalho diferenciadas, o Sabin conseguiu reduzir bastante a fuga dos profissionais, atraídos por concursos públicos. Entre 2005 a 2007, seu tunover caiu de 28\% para 9\% ao ano" (REVISTA, 2008, p.84).

Quanto ao absenteísmo ele é evidenciado principalmente no número de apresentação de atestados médicos que possam tornar a falta justificada ao trabalho e, nesse sentido, impedir o desconto do tempo parado nos salários. O serviço de saúde oferecido no ambulatório da empresa é poderoso para o controle dessas apresentações. Outro contraponto à saúde, essa ação de investir no próprio ambulatório é, também, de cooperar para o controle e redução de faltas, como vemos na MASA, “A preocupação com o bem-estar continua no Programa Vida Saudável, criado há três anos. Há acompanhamento médico, nutricional e psicológico, e metas de melhoria nos 
indicadores de saúde. A adesão é voluntária, hoje é de 75\%. "A queda do absentismo é sensível", afirma o diretor de RH" (REVISTA, 2007, p.60).

Chama a nossa atenção a adoção de práticas como o emociograma e a terapia do riso porque fazem crer que os problemas de saúde mental (fadiga, desânimo, exaustão emocional) do trabalhador são determinados por problemas familiares ou intrínsecos a ele, como que deixando às "sombras" as condições de trabalho, como vemos nesse trecho da Albras:

Durante seis meses, todos os 1300 funcionários responderam a um questionário individual [...]. As perguntas serviam para avaliar o nível de tensão do pessoal. O resultado, apresentado para toda a empresa, constatou um grau elevado de estresse. Iniciou-se, então, um treinamento com técnicas e comportamentos adequados para gerir melhor o cansaço e as pressões do dia-a-dia. "As pressões não diminuíram, o que mudou foi a forma como a gente lida com elas", comentam os funcionários.

Saúde e qualidade de vida são, de fato, preocupação da empresa. Há dois anos e meio foi implantado o Programa Vida Saudável. Os funcionários interessados passam por avaliação médica, nutricionais, psicológicas e físicas. A partir daí são estipuladas as metas e os participantes recebem acompanhamento no período. O resultado não podia ser melhor. Desde o começo do programa, houve redução de $90 \%$ no absenteísmo, aumento da produtividade e redução dos custos com assistência médica. [...].

Vantagem: oferece ótimas condições de trabalho e monitora o nível de estresse dos funcionários.

Desvantagem: ainda há gestores que abusam da autoridade e geram pressão desnecessária. (REVISTA, 2006, p.86-87) (grifo nosso)

A pesquisa sobre o estresse indicou o elevado índice em todos os trabalhadores da referida empresa. De tal modo, verificamos no texto que o controle do estresse recai principalmente pelo manejo de técnicas que o trabalhador deve aprender e aplicar, parecem não existir um estudo que avalie a natureza e as condições do trabalho que estão submetidos os trabalhadores. Segundo Rodrigues (1992 apud LIMONGI-FRANÇA; ARELLANO, 2002, p.301) "não há qualidade de vida no trabalho se as condições em que se trabalha não permitem viver em nível tolerável de estresse, de preferência tendo como meta o eustresse (o lado bom do estresse), e não o distresse, tensão nervosa nociva que gera, entre outros, os distúrbios psicossomáticos".

No trecho transcrito anteriormente reconhecemos como nocivos, o estilo da liderança ("há gestores que abusam da autoridade e geram pressão desnecessária"), as condições de trabalho que são as jornadas, as metas impostas e o tempo no trabalho, conforme o trecho extraído da ABB, "[...] onde os 3000 funcionários dão duro de 10 a 12 horas por dia. Toda essa gente precisa de, bem, muita energia para garantir os bons rendimentos da empresa [...]. Para deixar os funcionários cheios de saúde a ABB oferece diversas opções. Algumas delas: programa de 
qualidade de vida com pesquisa, avaliação física e orientação de nutricionistas" (REVISTA, 2000, p.50).

Embora havendo incrementos por parte das empresas para que o trabalhador tenha a sensação de bem-estar, ainda sobressaem às condições insatisfatórias do "chão da fábrica", como vemos a seguir:

As salas de descanso, com ar-condicionado e poltronas reclináveis, estão entre as mordomias. 'No turno da noite pode até cochilar um pouco mais', diz um colaborador. Há também programas de controle de doenças crônicas e acompanhamento à gestante. Os participantes são atendidos na empresa por médico, nutricionista e preparador físico, e não pagam os remédios. Quase todos os projetos de saúde e bem-estar da Masa abrangem famílias dos funcionários.

Ponto negativo: alguns funcionários ainda reclamam do calor excessivo na linha de produção da empresa. (REVISTA, 2007, p.60) (grifo nosso)

\section{CONCLUSÃO}

Concluímos que as ações adotadas pelas empresas favorecem sim a saúde do trabalhador, contudo, recomenda-se a análise sistemática e aprofundada da natureza do trabalho, das condições, das metas de produção, das jornadas de trabalho, dos estilos de liderança e das políticas de pessoal, pois, estes elementos colaboram para a promoção de doenças e o seu agravamento. Embora tenhamos elegido nessa pesquisa o gênero textual que visa à divulgação das melhores empresas para se trabalhar, poderíamos ter "achados" que favorecessem exclusivamente a imagem positiva dessas, porém foi possível identificar as ações e estabelecer contrapontos mesmo em documentos que teriam por natureza focar o olhar na face exteriorizada das organizações.

\section{REFERÊNCIAS}

BARDIN, L. Análise de conteúdo. Lisboa: Edições 70, 1979.

BORGES, L. O.; GUIMARÃES, L. A. M.; SILVA, S S. Diagnóstico e promoção da saúde psíquica no trabalho. In. BORGES, L.O; MOURÃO, L. (Org.). O trabalho e as organizações: atuações a partir da psicologia. Porto Alegre: Artmed, 2013. p.581-618

CHIAVENATO, I. Gestão de pessoas: o novo papel de recursos humanos nas organizações. Rio de Janeiro: Campus, 2004.

CHANLAT, J.F. Modos de gestão, saúde e segurança no trabalho. In. DAVEL, E.; VASCONCELOS, J, (Org.). "Recursos humanos" e subjetividade. Petrópolis, RJ: Vozes, 1995. p.118-128. 
CODO, W.; SORATTO, L.; MENEZES, I.V. Saúde mental e trabalho. In. ZANELLI, J.C.; BORGESANDRADE, J.E.; BASTOS, A.V.B. Psicologia, organizações e trabalho no Brasil. (Org.). Reimpressão. Porto Alegre: Artmed. p.276-299

GIL, A. C. Métodos e técnicas de pesquisa social. 6. ed. São Paulo: Atlas, 2008.

LIMA, M.C.A. A pesquisa em saúde mental e trabalho. In. CODO, W.; TAMAYO, A.; BORGESANDRADE, (Org.). Trabalho, organizações e cultura. São Paulo: Autores Associados, 1997. p.49-59

LIMONGI-FRANÇA, A. C.; ARELLANO, E. B. Qualidade de vida no trabalho. In. LEME, M.T. (Org.). As pessoas nas organizações. São Paulo: Gente, 2002. p.295-306

REVISTA. As melhores empresas para se trabalhar. Revista Exame, Editora Abril, São Paulo, 20002010.

SILVA, E. S. A inter-relação trabalho-saúde mental: um estudo de caso. Revista de Administração de Empresa, São Paulo, v. 32, n.4, p.70-90, set./out. 1992.

SPINK, P. Análise de documentos de domínio público. In. SPINK, M. J. (Org.). Práticas discursivas e produção de sentidos no cotidiano: aproximações teóricas e metodológicas. 6. ed. São Paulo: Cortez, 2004. p. 123-151 